Volume 14 - Número 2 - ago/dez de 2019

\title{
UMA ANÁLISE DE MATERIAIS DIDÁTICOS (RE)ELABORADOS NO PROJETO DE EXTENSÃO "UNISALE PARCERIA UNIVERSIDADE-ESCOLA" À LUZ DOS MULTILETRAMENTOS
}

\section{AN ANALYSIS OF DIDACTIC MATERIALS (RE)ELABORATED IN THE EXTENSION PROJECT “UNISALE UNIVERSITY-SCHOOL PARTNERSHIP" IN THE LIGHT OF MULTILITERACIES}

\author{
Isabela de Oliveira Campos ${ }^{1}$ \\ Sarah Linhares Oliveira ${ }^{2}$
}

\begin{abstract}
RESUMO: Este artigo tem como propósito analisar os materiais didáticos (re)elaborados a partir de uma parceria estabelecida dentro do projeto de extensão "UNISALE Parceria Universidade-Escola" à luz da teoria dos multiletramentos. O projeto é parte integrante do Programa Interfaces, da Faculdade de Letras da UFMG e tem atuado para que seja possível unir duas instituições de ensino, a escola básica e a universidade, em prol da melhoria de suas relações. Para a análise, foram selecionados dois planos de aula com seus respectivos materiais elaborados durante uma parceria no ano de 2018. As análises apontam que ambos os materiais contemplaram os principais aspectos da teoria dos multiletramentos, ainda que em diferentes graus e de diferentes maneiras. Salientamos também aspectos que podem ser mais bem explorados dentro das (re)elaborações didáticas. Ademais, há indícios de que os materiais (re)elaborados nessa parceria contribuíram para uma junção bem-sucedida da teoria e da prática, entendidas sócio-historicamente como dois polos distantes.
\end{abstract}

PALAVRAS-CHAVE: Parceria universidade-escola. Material didático. Multiletramentos. Língua inglesa.

ABSTRACT: This article aims to analyse some didactic materials (re)elaborated in a partnership established in the project UNISALE University-School Partnership in the light of multiliteracies theory. The project is part of the Interfaces Program at FALE/UFMG and it has acted to unite the basic school and the university in order to improve their relationship. For the analysis, two lesson plans elaborated during a partnership in 2018 and their respective materials were selected. The analyses indicate that both materials have contemplated the main features of multiliteracies theory, although in different degrees and in different ways. We also pointed out some aspects that could be better explored within the didactic (re)elaborations. In addition, there are indications that the materials (re)elaborated in this partnership have contributed to a successful connection between theory and practice, that have been socio-historically understood as two distant poles.

KEYWORDS: University-school partnership. Didactic material. Multiliteracies. English.

\section{Introdução}

Os materiais didáticos têm papel fundamental na vida de qualquer professor, incluindo o professor de língua inglesa (LI), uma vez que sua escolha, (re)elaboração e adaptação são tarefas de suma importância na vida desse profissional, visto que é o material que guiará o planejamento das aulas e, principalmente, refletirá as visões e representações que o professor possui sobre língua, práticas de ensino e educação.

Além disso, a escolha do material pode ser entendida como um ato político consciente ou inconsciente - a partir do momento que o professor escolhe trabalhar determinados tópicos em detrimento de outros, assim como o modo como eles serão trabalhados. Aqui, cabe ressaltar que entendemos material didático a partir de Tomlinson (2011), que o define como qualquer instrumento que possa ser utilizado para aumentar o conhecimento e a experiência dos alunos, seja ele um livro didático, um plano de aula, um vídeo do YouTube, um exercício criado pelo professor ou um jogo desenvolvido pelos alunos.

\footnotetext{
${ }^{1}$ Doutoranda do Programa de Pós-Graduação em Estudos Linguísticos da Universidade Federal de Minas Gerais. Mestra em Linguística Aplicada pela mesma instituição. E-mail: isabelacamposufmg@gmail.com

${ }_{2}$ Mestra em Linguística Aplicada pela Universidade Federal de Minas Gerais. E-mail: sarahloliveira@gmail.com
} 
Volume 14 - Número 2 - ago/dez de 2019

Ao concordarmos que o material didático desempenha um papel fundamental no ensino-aprendizagem de LI, questionamo-nos: de que forma podemos propiciar oportunidades tanto na formação inicial quanto na formação continuada de professores de LI a respeito da (re)elaboração de materiais didáticos? E como aproximar os embasamentos teóricos produzidos na universidade da realidade do dia a dia escolar?

Algumas iniciativas nessa direção têm surgido nos últimos anos em universidades brasileiras. Na Universidade Federal de Minas Gerais, o projeto de extensão da Faculdade de Letras denominado UNISALE Parceria Universidade-Escola ${ }^{3}$ propõe uma ressignificação da relação entre essas duas instituições de ensino, visando "diminuir a distância histórica e verticalizada entre a escola regular e a universidade, que, nessa nova configuração, são vistas como parceiras, que caminham juntas para traçar e atingir objetivos comuns" (REIS et al., 2019, p. 287), em prol do aprimoramento do ensino-aprendizagem da LI.

Desse modo, ao propor um trabalho colaborativo entre parceiros dessas duas instituições na sala de aula de LI da escola regular pública, evidentemente surge a necessidade de se trabalhar com a análise crítica dos materiais didáticos disponíveis à luz de teorias da Linguística Aplicada, utilizando preceitos da Pesquisa-Ação Colaborativa (SAGOR, 1993), que se configura como metodologia base do projeto UNISALE, fornecendo um direcionamento teórico-metodológico para o trabalho dos parceiros.

No presente artigo, objetivamos analisar a (re)elaboração e produção de material didático para o ensino-aprendizagem de LI em uma parceria universidade-escola dentro do projeto UNISALE ${ }^{4}$, com o intuito de observar de que maneira os pressupostos teóricos dos multiletramentos encontram-se presentes. É mister ressaltar que o projeto tem como um de seus objetivos diminuir a visão histórica de que a universidade é o lugar da teoria, e a escola, o local da prática, rumo a uma práxis docente mais bem-sucedida no encontro desses dois polos, e por isso a análise dos materiais à luz de teorias como a dos multiletramentos ressalta um dos propósitos do UNISALE.

O texto encontra-se dividido em subseções: primeiramente, faremos uma breve exposição da fundamentação teórica que nos norteia. Em seguida, discutiremos a metodologia, faremos a discussão dos dados e, por fim, teceremos algumas considerações finais.

\section{A teoria dos multiletramentos}

É evidente que o mundo de hoje se transformou e continua se transformando em grande velocidade a partir do advento das tecnologias digitais e de uma globalização acelerada, fruto dessas tecnologias (DIAS, 2015; CATTO, 2013; DUBOC; FERRAZ, 2011). Tornamonos sujeitos mais fluidos, com fronteiras dissolvidas e identidades desestabilizadas. No entanto, a escola tem encontrado grandes dificuldades para se transformar diante desse cenário, assim como suas práticas e currículos (LIBERALI et al., 2015).

A partir dessa necessidade de (trans)formação do ensino-aprendizagem no século XXI, o termo "multiletramentos" surgiu fruto de um encontro entre dez pesquisadores que se reuniram na cidade de Nova Londres, Inglaterra, em 1994, para discutir sobre o futuro da educação e da pedagogia dos letramentos em um mundo de crescentes e rápidas mudanças. Encabeçado por Mary Kalantzis e Bill Cope, o The New London Group, ou Grupo de Nova Londres, também era composto por Courtney Cazden, Norman Fairclough, Jim Gee, Gunther Kress, Allan Luke, Carmen Luke, Sarah Michaels e Martin Nakata. Dessa reunião resultou a

\footnotetext{
${ }^{3}$ O Projeto UNISALE Parceria Universidade-Escola é parte integrante do Programa Interfaces da Formação em Línguas Estrangeiras da Faculdade de Letras (FALE) da Universidade Federal de Minas Gerais (UFMG) e é coordenado pela Profa. Dra. Valdeni da Silva Reis. Mais informações sobre o projeto no endereço eletrônico: http://www.letras.ufmg.br/unisale/.

${ }^{4}$ Como denominaremos o projeto UNISALE: Parceria Universidade-Escola daqui em diante.
} 
Volume 14 - Número 2 - ago/dez de 2019

primeira publicação do grupo que apresenta o termo "multiletramentos": o artigo "A Pedagogy of Multiliteracies: Designing Social Futures", publicado na Harvard Educational Review, em 1996 (COPE; KALANTZIS, 2000).

De acordo com Kalantzis e Cope (2012), a escolha pelo termo "multiletramentos" deve-se ao fato de esse conceito abranger dois aspectos importantes. O primeiro deles é a diversidade social, que se refere à grande diversidade linguística e cultural proveniente dos mais variados contextos, já que a construção de sentido e significado depende grandemente e varia significativamente de acordo com o contexto social e cultural no qual é produzido. O segundo aspecto é a multimodalidade, que compreende as novas tecnologias e as novas maneiras de se comunicar, abrangendo os modos escrito, visual, espacial, oral, auditivo, gestual e tátil, já que atualmente a comunicação ocorre em meios cada vez mais multimodais. Desse modo, os dois "multi" de "multiletramentos", de acordo com Kalantzis e Cope (2012), seriam o multicontexto e o multimodal.

Assim, a pedagogia dos multiletramentos surge como um complemento às pedagogias tradicionais de letramento, cujo foco era apenas na língua em si - geralmente em apenas uma variação desta -, que, por sua vez, era comumente concebida como um sistema estável e fechado (KALANTZIS; COPE, 2012). A pedagogia dos multiletramentos vai muito além da língua per se, pois considera as diferentes culturas e os contextos sociais como fatores significativos, que afetam diretamente os modos de representação de cada sociedade, e isso inevitavelmente influencia a língua, que passa a ser compreendida como mutável, flexível e fluida. Ademais, a pedagogia dos multiletramentos volta os olhares para a importância do desenvolvimento e da formação do aluno para uma cidadania crítica e ativa, para que sejam agentes de seus próprios processos de conhecimento e tenham a capacidade de realizar suas contribuições no mundo (KALANTZIS; COPE, 2012).

Além disso, no atual cenário global, é impossível não considerar o impacto que a internet tem gerado na vida das pessoas, principalmente no que diz respeito ao processo de comunicação e de construção de significados, levando em conta os múltiplos modos textuais presentes em nosso dia a dia (DIAS, 2015; CATTO, 2013; COPE; KALANTZIS, 2000). Com o advento da internet, surgiram - e continuam surgindo a cada dia - novas maneiras de se comunicar, em meios que são cada vez mais multimodais e interativos, que não contemplam apenas o texto escrito, mas abrangem as mais variadas formas textuais, incluindo vídeos, sons, imagens, entre tantos outros.

De acordo com Kalantzis e Cope (2012), os novos meios de comunicação estão remodelando as maneiras como usamos a língua, e, para lidarmos com tantas mudanças, é preciso recorrermos ao letramento multimodal. Dias (2012, p. 864) define o letramento multimodal como a "capacidade do indivíduo para lidar com os textos multimodais, tanto os impressos quanto os digitais, da era contemporânea". Segundo a mesma autora (DIAS, 2015, p. 305), a globalização e a internet tiveram um impacto enorme na sociedade, gerando "novas identidades para os textos impressos e digitais e novas formas de ensinar inglês". Assim, acreditamos que, ao (re)elaborar os materiais didáticos a serem aplicados no ensino de LI, o professor deve levar em consideração os múltiplos modos semióticos que podem estar presentes nos textos. Cabe também ao letramento multimodal o papel de auxiliar os alunos nesse processo de explorar os recursos de um texto, pois cada modo semiótico irá proporcionar diferentes recursos e potencialidades, que, por sua vez, serão explorados de diferentes maneiras, a depender de cada leitor.

Ainda dentro da pedagogia dos multiletramentos, Kalantzis e Cope (2012) propõem uma gama de atividades que podem ser produtivas ao se colocar a pedagogia dos letramentos em prática no contexto escolar. Tais atividades, denominadas processos de conhecimento, são compostas de quatro tipos de processo: experienciar, conceituar, analisar e aplicar. O processo de experienciar está relacionado à exploração das experiências dos alunos, tanto em relação a 
Volume 14 - Número 2 - ago/dez de 2019

seus conhecimentos prévios quanto em relação aos novos. Conceituar é o processo de nomear, classificar e definir termos. Analisar é o processo de avaliar criticamente uma situação, relacionando causas e efeitos. Por fim, aplicar significa colocar os conhecimentos em prática, seja no mundo real, seja por meio de situações simuladas, para que os alunos possam expressarse e trazer suas contribuições ao mundo.

\section{Metodologia e framework de análise}

A fim de analisarmos os materiais didáticos (re)elaborados em uma parceria universidade-escola no projeto UNISALE, selecionamos dois planos de aula para serem examinados neste trabalho: uma elaboração e uma adaptação do livro didático. ${ }^{5}$ Pautamo-nos nos dois termos "guarda-chuvas" dos multiletramentos para a construção do nosso framework de análise: o multicontexto e o multimodal.

Objetivamos, assim, fornecer uma análise à luz da teoria dos multiletramentos sobre esses materiais didáticos, com o intuito de divulgar o trabalho realizado no referido projeto de extensão, além de identificar e sugerir possíveis caminhos para desenvolver e fortalecer teoricamente o que já é feito quando se trata da (re)elaboração dos materiais didáticos nas parcerias universidade-escola dentro do projeto.

\section{Contextualização e participantes}

Os materiais a serem analisados foram desenvolvidos em uma parceria entre uma bolsista do UNISALE, mestranda do Programa de Pós Graduação em Estudos Linguísticos da $\mathrm{UFMG}^{6}$ e uma professora da rede pública de ensino da cidade de Belo Horizonte/MG, graduada em Letras pela UFMG e pós-graduada em Neurociência pela mesma instituição. A parceria aconteceu no período de abril a outubro de 2018, em uma escola pública da zona Norte da cidade, e contou com visitas da bolsista à escola, observações de aulas, sessões de diálogo e reflexão entre as parceiras e a produção e adaptação de materiais didáticos de acordo com as demandas do contexto verbalizadas pela professora e observadas pela bolsista, além do objetivo do projeto de promover um ensino-aprendizagem de LI mais crítico e significativo. As quatro turmas participantes do projeto eram do $1^{\circ}$ ano do ensino médio, com alunos entre 14 a 18 anos, sendo a maioria natural de Belo Horizonte.

Nos dias de visita da bolsista à escola, as parceiras utilizavam o horário de módulo ${ }^{7}$ da docente para discutirem a reelaboração e adaptação dos materiais didáticos. Nessas discussões as parceiras debatiam as possibilidades apresentadas pelo material e o suplementavam, adaptavam e reorganizavam de acordo com objetivos didático-pedagógicos definidos anteriormente. Tais reflexões e decisões eram amparadas por textos teóricos lidos e compartilhados entre as parceiras ${ }^{8}$ e, finalmente, os planos de aula e os materiais necessários eram finalizados em colaboração entre elas por meio da internet.

\footnotetext{
${ }^{5}$ MENEZES, V.; BRAGA, J.; GOMES, R.; CARNEIRO, M.; RACILAN, M.; VELOSO, M. Alive High Língua Estrangeira Moderna Inglês: $1^{\circ}$ Ano do Ensino Médio. São Paulo: SM, 2016.

${ }^{6}$ Também uma das autoras deste artigo.

${ }^{7} \mathrm{O}$ horário de módulo faz parte da carga horária do professor do estado de Minas Gerais e é definido como o horário destinado a atividades extraclasse. Fonte: https://designacao-see-mg.com.br/wpcontent/uploads/2018/01/RESOLUCAO-SEE-N-3-660-DE-1-DE-DEZEMBRO-DE-2017.pdf.pdf. Acesso: out. 2019.

8 A título de exemplo: Essential Teacher Knowledge: Core Concepts in the English Language Teaching (HARMER, 2012) e Ensino de inglês como língua estrangeira na escola pública: letramentos, globalização e cidadania (MATTOS, 2015).
} 
Volume 14 - Número 2 - ago/dez de 2019

\section{Análise dos materiais didáticos}

A primeira atividade, denominada "Where are these people from?" (Apêndice A), teve como objetivos principais o desenvolvimento dos letramentos em relação ao processo de leitura e da comunicação oral, além do objetivo de planejar aulas que trabalhassem a criticidade com os alunos, uma demanda especificada pela professora no início da sua participação no projeto UNISALE.

Podemos identificar nesse plano de aula vários elementos relacionados aos multiletramentos, como na etapa de Pre-teach Vocabulary, quando é requisitado aos alunos que utilizem seus celulares para pesquisar a tradução de palavras específicas que irão encontrar na leitura, com o intuito de auxiliá-los a compreender melhor o texto. Kalantzis e Cope (2012) ressaltam a importância de os alunos pesquisarem informações em diferentes fontes, trabalharem com a internet e terem maior responsabilidade em seu processo de aprendizagem. É evidente que o uso do celular não é permitido em alguns contextos educacionais, e, no caso dessa parceria, apesar de ser permitido, a escola não possuía rede WiFi capaz de suportar o grande número de alunos. Em todo caso, alguns alunos possuíam aplicativos de dicionários offline instalados no celular, e outros utilizaram dados móveis para acessar a internet.

Há também uma análise funcional do gênero digital Wikipedia, na etapa Setting the Context: Text from Wikipedia, compreendendo sua função social e suas características peculiares - uma enciclopédia editável. Segundo Kalantzis e Cope (2012), a abordagem funcional dos letramentos foca em ensinar aos alunos textos que lhes permitirão ter sucesso na escola e na vida em sociedade. Dessa forma, a abordagem funcional focaliza a estrutura dos diferentes gêneros textuais e o modo como produzem significados, servindo a diferentes propósitos, o que vai ao encontro do multicontexto, ao trabalharmos com um gênero que contempla uma diversidade linguística e cultural, em que diferentes indivíduos podem ter acesso a uma escrita e uma construção e negociação de sentidos compartilhada, e também do multimodal, ao abordarmos um gênero digital.

O espaço para o desenvolvimento da criticidade do aluno também é identificado no material elaborado, na etapa denominada Critical Thinking Time, em que, através do exercício de decidir sobre a nacionalidade das pessoas famosas que aparecem no site Wikipedia, os estereótipos de raça e nacionalidade poderão ser evidenciados. Isso porque, propositalmente, as parceiras procuraram trazê-los à tona na elaboração do material, com a utilização de pessoas famosas brancas provenientes de países como África do Sul e de pessoas negras afroamericanas, por exemplo. Assim, a partir da reação de surpresa dos discentes ao tomarem conhecimento da origem dessas pessoas, a professora pôde discutir o conceito de estereótipo com os alunos, abordando a (re)produção de sentidos e práticas discursivas através de dois modos: o imagético e o textual. De acordo com Kalantzis e Cope (2012), o objetivo da criticidade nos letramentos é ajudar os alunos a compreenderem o modo como as coisas são construídas no mundo, por meio dos valores e das ações das pessoas, o que envolve levantar questões desafiadoras, controversas, políticas, etc.

Ademais, ao perguntar aos alunos como eles se decidiram sobre a nacionalidade dessas pessoas e por que eles o fizeram, há um espaço para a ressignificação de estruturas preconcebidas e representações de mundo. Tal estratégia pedagógica é denominada "momentos queer" - em uma releitura feita por Moita Lopes (2013) dos estudos de Alexander Doty, pesquisador pioneiro dos estudos queer - e tem como objetivo principal "estranhar sentidos solidificados sobre gênero e sexualidade com os quais operavam com o fim de se reorganizarem semanticamente sobre tais sentidos" (MOITA LOPES, 2013, p. 245). Nesse caso, o estranhamento se daria na questão racial e de estereótipos de nacionalidade, com o objetivo de causar uma perturbação sobre as visões essencialistas e naturalizadas que temos do mundo, principalmente quando discorremos sobre questões raciais, e "a compreensão racializada das 
Volume 14 - Número 2 - ago/dez de 2019

pessoas $[\ldots]$ entendida aqui como um ato performativo que as coloca em caixas bem definidas e delimitadas" (MOITA LOPES, 2013, p. 244).

Como Kalantzis e Cope (2012) argumentam, a pedagogia dos multiletramentos também estaria relacionada a uma agência dos aprendizes e à possibilidade de realizarem uma intervenção no mundo real de forma inovadora e criativa, enfatizada pelo processo de conhecimento "aplicar". Desse modo, a título de sugestão para esse plano de aula, a atividade poderia ter sido finalizada com a manipulação do gênero textual Wikipedia, em que os alunos teriam a oportunidade de criar sua própria biografia para o site. É claro que a viabilidade dessa tarefa deveria ser analisada de acordo com o contexto - se a escola possui um laboratório de informática, por exemplo -, podendo contar com uma escrita simulada, em forma de pôster, ou uma escrita realmente intervencionista, em que os alunos poderiam editar suas biografias no site Wikipedia ou em outro site similar, criando e compartilhando sentidos sobre eles nesse espaço virtual.

A segunda atividade, denominada "What does a clown doctor do?" (Apêndice B), foi reelaborada a partir de uma proposta presente no livro didático, que trazia um pôster, porém, com atividades que não exploravam esse gênero textual. Assim, a bolsista do projeto UNISALE e a professora decidiram reelaborar as atividades e produziram o plano de aula que também teve como objetivo principal o desenvolvimento dos letramentos em relação ao processo de leitura, além do trabalho com o gênero textual pôster e a discussão sobre trabalho voluntário.

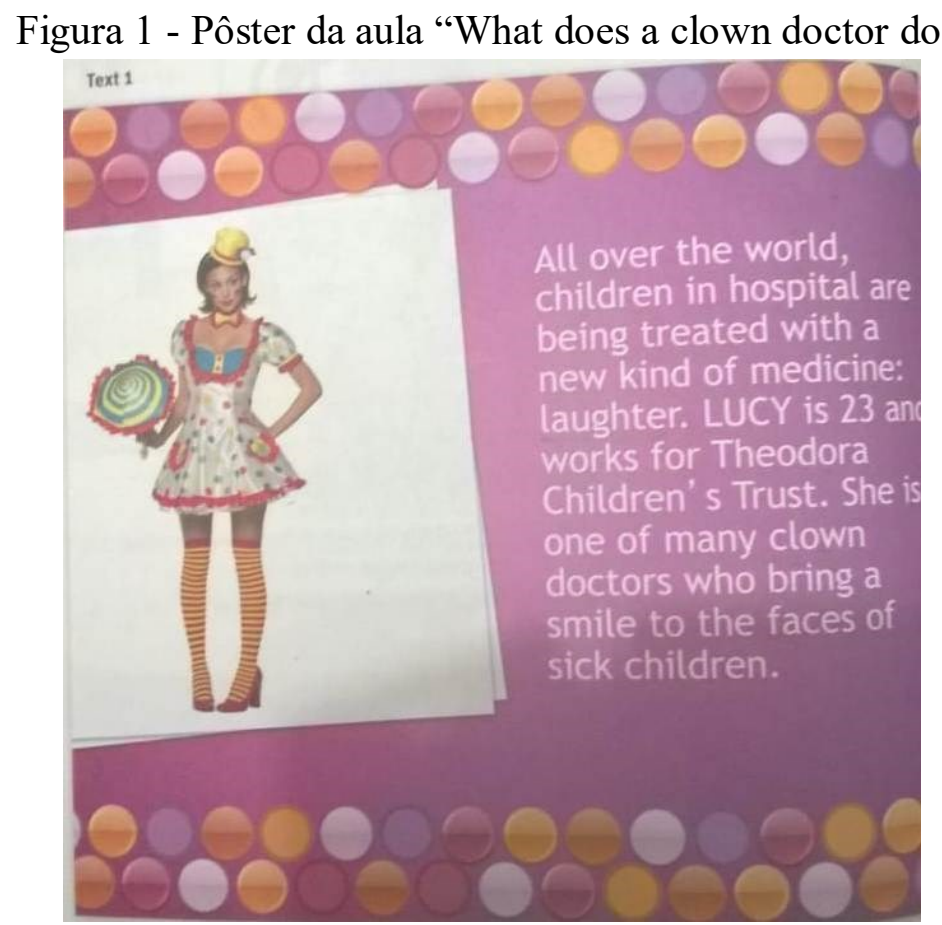

Fonte: Alive High Lingua Estrangeira Moderna Inglês: $1^{\circ}$ Ano do Ensino Médio, p. 14.

Podemos observar que a primeira atividade do material, denominada Lead in, trabalha e explora a imagem e as informações contidas no pôster, através de perguntas feitas pela docente, acionando as experiências e os conhecimentos prévios dos alunos sobre o tema proposto, com o objetivo de construir significados a partir dos sentidos que eles trazem para a sala de aula. Isso faz com que essa primeira parte esteja em consonância com o processo de conhecimento "experienciar", em que os alunos constroem e produzem significados através do "conhecido" e do "novo", valorizando suas perspectivas, ideias e informações que parecem similares a eles e conectando-as com novas informações que eles desconhecem. 
Volume 14 - Número 2 - ago/dez de 2019

Essa produção de significados se dá também por meio da multimodalidade, pois, ao explorarem o gênero pôster, os alunos têm contato com dois modos semióticos, o escrito e o visual, visto que o pôster traz a imagem de uma mulher vestida de Clown Doctor e um texto escrito sobre o tema. Assim, os dois modos semióticos em combinação - visual e escrito presentes no pôster potencializam o processo de construção de sentido por parte dos alunos acerca do gênero explorado.

O material analisado propõe uma reflexão com os alunos sobre o trabalho voluntário realizado pelos Clown Doctors, assim como instiga os próprios alunos, na proposta da última atividade - Going Beyond -, a pesquisarem mais sobre trabalhos voluntários e escolherem um local onde poderiam realizá-lo. Desse modo, a atividade busca promover o senso de cidadania com os alunos, estimulando-os a agirem na sociedade, o que se configura como uma das propostas dos multiletramentos, que visa engajar ativamente os alunos em práticas sociais.

No entanto, a título de sugestão, a atividade poderia ter ido além na produção de sentidos, ao requisitar, por exemplo, que os alunos produzissem algum tipo de material linguístico sobre o local que eles pesquisaram para realizar o trabalho voluntário, como um vídeo ou um pôster. Assim eles utilizariam a LI para construir significado sobre essas informações adquiridas e informar aos seus colegas sobre as possibilidades de voluntariado que eles encontraram em sua comunidade, empregando a LI na construção de sentidos sobre sua realidade e seu contexto. Outra sugestão estaria relacionada à participação ativa dos alunos no próprio espaço escolar na promoção de algum tipo de trabalho na escola, como cuidar da horta ou do jardim da instituição (ou criar, caso não houvesse), promover um mutirão de cuidados/limpeza em relação a ela, entre outros possíveis trabalhos voluntários com o intuito de engajar os alunos em uma participação ativa no ambiente escolar.

\section{Considerações finais}

Após analisarmos os dois materiais didáticos (re)elaborados no projeto UNISALE, podemos concluir que ambos contemplaram aspectos dos multiletramentos, ainda que de diferentes maneiras. Em relação ao multicontexto, ambos materiais apresentaram diversidades textuais para a construção de sentidos na nossa sociedade atual, corroborando o entendimento da linguagem como processo e colaboração na produção de significados. Ambos também objetivaram o desenvolvimento de cidadãos críticos e ativos, pois se ocuparam de elementos que promovem um ambiente para a reflexão discente e para o desenvolvimento do pensamento crítico e do senso de cidadania. Apesar das sugestões que fizemos para potencializar esse desenvolvimento, acreditamos que os materiais já tenham realizado uma boa tentativa nessa direção, e, sendo esse um aspecto de grande importância dentro da pedagogia dos multiletramentos, defendemos que a preocupação com a formação do aluno para a cidadania crítica e ativa precisa estar sempre presente no processo de (re)elaboração de materiais produzidos no projeto UNISALE.

Com relação à multimodalidade, os dois materiais focaram nos mesmos modos semióticos - o escrito e o visual -, já que ambos trabalharam com textos escritos e com imagens/fotos. Considerando a estrutura de muitas escolas da rede pública de ensino, que não possuem computadores com acesso à internet disponíveis aos alunos e oferecem uma estrutura limitada para o uso de aparelhos de multimídia, é compreensível que haja uma maior predominância dos modos escritos e visuais, visto que são os mais acessíveis. Porém, o trabalho com os múltiplos modos semióticos pode ser realizado de muitas maneiras, através de adaptações e também ao se explorarem os recursos que os alunos têm disponíveis fora da sala de aula. Nesse aspecto, acreditamos que a inclusão de novos modos semióticos poderia enriquecer os materiais elaborados no projeto UNISALE, além de proporcionar aos alunos a 
Volume 14 - Número 2 - ago/dez de 2019

oportunidade de ter contato com outros modos semióticos com os quais não estejam tão habituados, como o auditivo, o gestual, entre outros.

Por fim, acreditamos que o processo de (re)elaboração de materiais didáticos dentro dessa parceria universidade-escola tenha conseguido atender satisfatoriamente um dos objetivos do projeto UNISALE ao diminuir a distância sócio-historicamente construída entre prática e teoria, ressaltando que é possível uni-las em uma práxis docente. Também evidenciamos o desenvolvimento profissional das parceiras no contexto escolar em que elas estavam inseridas, o que culminou em um processo de reflexão da professora-parceira a respeito de quem são seus alunos e o que eles anseiam do ensino da LI, buscando promover uma real inclusão dos discentes da escola regular pública no ensino-aprendizagem da LI e uma oportunidade para a promoção de cidadãos críticos e agentes.

\section{Referências}

CATTO, N. R. A relação entre o letramento multimodal e os multiletramentos na literatura contemporânea: alinhamentos e distanciamentos. Fórum Linguístico, Florianópolis, v. 10, n. 2, p. 157-163, 2013.

COPE, B.; KALANTZIS, M. (Ed.). A Pedagogy of Multiliteracies: Learning by Design. London: Palgrave Macmillan, 2015.

COPE, B.; KALANTZIS, M. Literacies. Cambridge, UK: Cambridge University Press, 2012. COPE, B.; KALANTZIS, M. (Ed.). Multiliteracies: Literacy Learning and the Design of Social Futures. London: Routledge, 2000.

DIAS, R. Multimodalidade e multiletramento: novas identidades para os textos, novas formas de ensinar inglês. In: SILVA, K. A.; ARAÚJO, J. (Org.). Letramentos, discursos midiáticos e identidades: novas perspectivas. Campinas: Pontes, 2015, p. 305-325.

DIAS, R. WebQuests: tecnologias, multiletramentos e a formação do professor de inglês para a era do ciberespaço. Revista Brasileira de Linguística Aplicada - RBLA, Belo Horizonte, v. 12, n. 4, p. 861-881, 2012.

DUBOC, A. P.; FERRAZ, D. M. Letramentos críticos e formação de professores de inglês: currículos e perspectivas em expansão. Revista X, Curitiba, v. 1, p. 19-32, 2011. Número especial: Dossiê Letramentos e Multiletramentos no Ensino de Línguas e Literaturas.

HARMER, J. Essential Teacher Knowledge: Core Concepts in English Language Teaching. London: Pearson, 2012.

LIBERALI, F. et al. Projeto Digit-M-ED Brasil: uma proposta de desencapsulação da aprendizagem escolar por meio dos multiletramentos. Revista Prolíngua, João Pessoa, v. 10, n. 3, p. 2-17, 2015.

MATTOS, A. M. A. Ensino de inglês como língua estrangeira na escola pública: letramentos, globalização e cidadania. Jundiaí: Paco Editorial, 2015.

MOITA LOPES, L. P. Gênero, sexualidade, raça em contextos de letramentos escolares. In: MOITA LOPES, L. P. Linguística aplicada na modernidade recente: festschrift para Antonieta Celani. São Paulo: Parábola Editorial, 2013. p. 227-247.

REIS, V. S. et al. (Re)construindo saberes, fazeres e parcerias para a sala de aula de língua estrangeira. In: FINARDI, K. R. et al. (Org.). A diversidade de fazeres em torno da linguagem: universidades, faculdades e educação básica em ação. Campinas: Pontes; PPGELUFES, 2019. p. 283-296.

SAGOR, R. How to Conduct Collaborative Action Research. Alexandra: Virginia ASCD, 1993.

TOMLINSON, B. Materials Development in Language Teaching. Edited by Brian

Tomlinson. Cambridge: Cambridge University Press, 2011. 
Volume 14 - Número 2 - ago/dez de 2019

APÊNDICE A

\begin{tabular}{|c|c|c|c|c|}
\hline \multicolumn{5}{|c|}{ LESSON PLAN: WHERE ARE THESE PEOPLE FROM? } \\
\hline STEPS/OBJETIVES & TIMING & PROCEDURES & INTERACTION & MATERIAL \\
\hline Lead in & 3 minutes & $\begin{array}{l}\text { Put up the photos from } \\
\text { the famous people on } \\
\text { the board and ask SS } \\
\text { where they think these } \\
\text { people are from. } \\
\text { Don't tell them the } \\
\text { answers. }\end{array}$ & $\mathrm{T}-\mathrm{SS}$ & $\begin{array}{l}\text { Board and } \\
\text { photos }\end{array}$ \\
\hline Pre teach vocabulary & 5 minutes & $\begin{array}{l}\text { Tell students that } \\
\text { before we read some } \\
\text { information about these } \\
\text { people, we will check } \\
\text { some vocabulary. } \\
\text { Write down these } \\
\text { words on the board: } \\
\text { PRIZES, MARRIED, } \\
\text { SIBLINGS, } \\
\text { HOMESCHOOLED } \\
\text { and CAREER. Ask SS } \\
\text { to use their mobile } \\
\text { phones to check the } \\
\text { translation of the } \\
\text { words. Write them } \\
\text { down on the board next } \\
\text { to the words. } \\
\text { Check with the class } \\
\text { and drill the } \\
\text { pronunciation of the } \\
\text { words. }\end{array}$ & $\mathrm{T}-\mathrm{SS}$ & Board \\
\hline $\begin{array}{l}\text { Setting the Context: } \\
\text { Text from Wikipedia }\end{array}$ & 3 minutes & $\begin{array}{l}\text { Call SS' attention to the } \\
\text { source of the text: } \\
\text { Wikipedia. Ask if they } \\
\text { know this website, if } \\
\text { they use it and what we } \\
\text { can find there. }\end{array}$ & $\mathrm{T}-\mathrm{SS}$ & \\
\hline $\begin{array}{l}\text { Reading for gist / } \\
\text { Critical Thinking Time }\end{array}$ & 9 minutes & $\begin{array}{l}\text { Ask SS to read the text } \\
\text { and fill in the blanks } \\
\text { with the country they } \\
\text { think these people are } \\
\text { from. } \\
\text { Monitor SS to assist } \\
\text { them when needed. }\end{array}$ & $\mathrm{S}$ & Handout \\
\hline
\end{tabular}


Volume 14 - Número 2 - ago/dez de 2019

\begin{tabular}{|c|c|c|c|c|}
\hline & & $\begin{array}{l}\text { Ask them to check in } \\
\text { pairs. } \\
\text { Then, check with the } \\
\text { class. } \\
\text { According to their } \\
\text { answers, ask them how } \\
\text { they chose them and } \\
\text { why they chose the way } \\
\text { they did. Introduce the } \\
\text { notion of } \\
\text { STEREOTYPE and } \\
\text { talk briefly about it, if it } \\
\text { is necessary. }\end{array}$ & $\begin{array}{l}S-S \\
T-S\end{array}$ & \\
\hline $\begin{array}{l}\text { Reading for specific } \\
\text { information I }\end{array}$ & 5 minutes & $\begin{array}{l}\text { Now, ask SS to unfold } \\
\text { the handout and answer } \\
\text { cirle the best option on } \\
\text { exercise } 2 \text { according to } \\
\text { the text. } \\
\text { Monitor SS to assist } \\
\text { them when needed. } \\
\text { Ask them to check in } \\
\text { pairs. } \\
\text { Then, check with the } \\
\text { class. }\end{array}$ & $\begin{array}{l}\mathrm{S} \\
\mathrm{S}-\mathrm{S} \\
\mathrm{T}-\mathrm{SS}\end{array}$ & Handout \\
\hline Controlled Speaking & 10 minutes & $\begin{array}{l}\text { Write on the board: } \mathrm{Q}= \\
\text { question, A = answer. } \\
\text { Tell SS they are going } \\
\text { to ask and answer the } \\
\text { questions on exercise } 4 . \\
\text { Firstly, they will do it } \\
\text { in pairs, then in groups } \\
\text { of } 4 \text { and then in groups } \\
\text { of } 8 \text { (standing up). } \\
\text { Drill the questions and } \\
\text { answer before they } \\
\text { start. } \\
\text { Monitor and control the } \\
\text { activity. } \\
\text { After that, elicit the } \\
\text { answers from SS. }\end{array}$ & SS - SS & \\
\hline
\end{tabular}




\section{Where are these people from?}

1) Read the texts taken from Wikipedia and, according to your opinion, fill in the blanks with the country each people are from: Colombia, Italy, the USA and South Africa.

Serena Williams (born September 26, 1981) is a 37 -year-old professional tennis player from She has four sisters and she started playing tennis at the age of 3 . When she was 14 years old, she played her first professional game as a tennis player. She has won many prizes during her career.

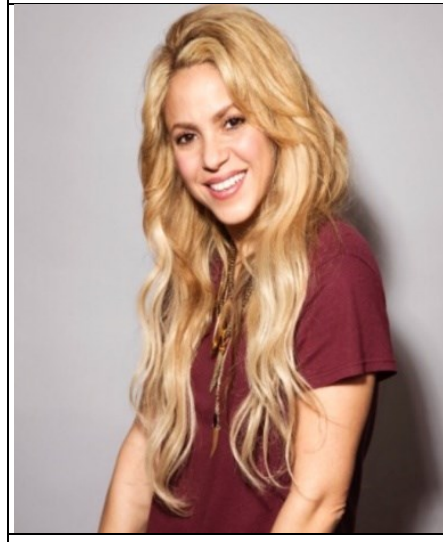

Shakira Isabel Mebarak Ripoll (born 2 February, 1977) is a singer, songwriter and dancer from She started singing and dancing at school and became one of the most successful singers in the English language in 2002. Shakira is married to the football player, Gerard Piqué, and has 2 children. She also speaks six languages: Spanish, Arabic, Portuguese, English, French and Italian.

Sasha Pieterse (born February 17, 1996) is an actress from . She is best known for her role as Alisson DiLaurentis in the TV series Pretty Little Liars. She was homeschooled and graduated at the age of 14 . She got married last month to her boyfriend, Hudson Sheaffer.

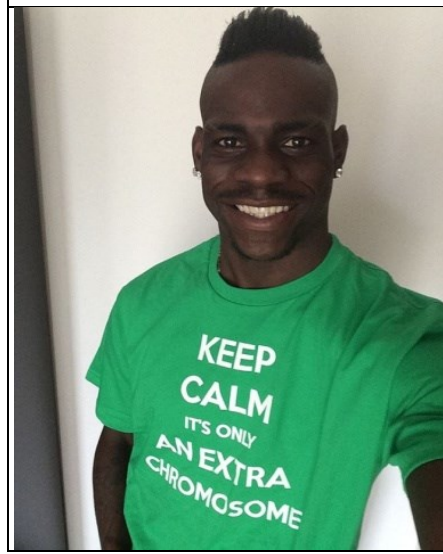

Mario Botelli (born August 12, 1990) is football player from . He has three biological siblings and was adopted by another family. He began to play football when he was 15 and the first famous football team he played for was Internazionale. He has played in many European Championships and nowadays he plays for the team Nice, in France. 
2) Read the text again and circle the best option:

a) Who is married? Serena Williams Sasha Pieterse

b) Who was adopted when he/she was a child? Shakira Mario Botelli

c) Who has four siblings? Serena Williams Mario Botelli

d) Who speaks six languages? Shakira Sasha Pieterse

3) Answer the questions orally:

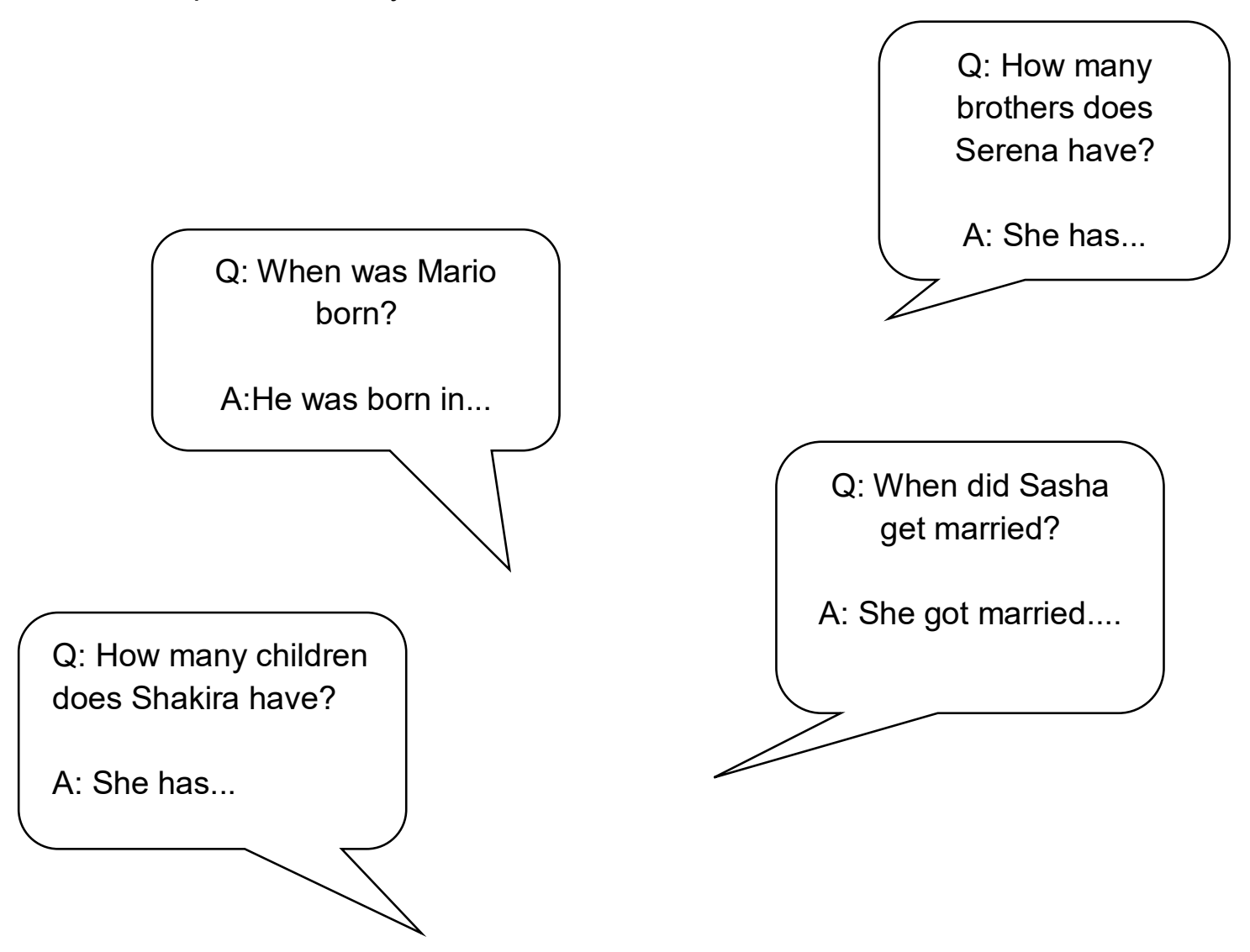

\section{GOING BEYOND...}

According to the text, say if the sentences are true $(T)$ or false $(F)$ :

a) Sasha Pieterse didn't go to school.

b) Serena Williams has never won any prizes.

c) Mario Botelli plays in Europe.

d) Shakira sang and danced when she was at school. 
Volume 14 - Número 2 - ago/dez de 2019

\section{APÊNDICE B}

\begin{tabular}{|c|c|c|c|c|}
\hline \multicolumn{5}{|c|}{ LESSON PLAN: WHAT DOES A CLOWN DOCTOR DO? } \\
\hline STEPS/OBJETIVES & TIMING & PROCEDURES & INTERACTION & MATERIAL \\
\hline Lead in & 3 minutes & $\begin{array}{l}\text { Ask SS to open their } \\
\text { books to page } 14 \text { and } \\
\text { exploit the poster } \\
\text { with them asking } \\
\text { questions about the } \\
\text { girl in the picture } \\
\text { (who's she? / what's } \\
\text { her job?, etc.) }\end{array}$ & $\mathrm{T}-\mathrm{SS}$ & Book page 14 \\
\hline Pre teach vocabulary & 7 minutes & $\begin{array}{l}\text { Tell students that } \\
\text { before we read the } \\
\text { information about the } \\
\text { girl, we will check } \\
\text { some vocabulary in } \\
\text { it. } \\
\text { In pairs, ask SS to try } \\
\text { to match the words to } \\
\text { the pictures / } \\
\text { definitions. } \\
\text { Check with the class } \\
\text { and drill the } \\
\text { pronunciation of the } \\
\text { words }\end{array}$ & $\begin{array}{l}\mathrm{S}-\mathrm{S} \\
\mathrm{T}-\mathrm{SS}\end{array}$ & Handout \\
\hline Hint & 3 minutes & $\begin{array}{l}\text { Call SS' attention to } \\
\text { the HINT on the top } \\
\text { right of the page and } \\
\text { mention that this is a } \\
\text { skill to be developed } \\
\text { especially for tests } \\
\text { like ENEM. }\end{array}$ & $\mathrm{T}-\mathrm{SS}$ & Book page 14 \\
\hline Reading for gist & 5 minutes & $\begin{array}{l}\text { Ask SS to read the } \\
\text { text and answer the } \\
\text { question "What's } \\
\text { Lucy's job / } \\
\text { profession?" (write } \\
\text { the question on the B) } \\
\text { Monitor SS to assist } \\
\text { them when needed. } \\
\text { Ask them to check in } \\
\text { pairs. }\end{array}$ & $S-S$ & Book page 14 \\
\hline
\end{tabular}


Volume 14 - Número 2 - ago/dez de 2019

\begin{tabular}{|c|c|c|c|c|}
\hline & & $\begin{array}{l}\text { Then, check with the } \\
\text { class. }\end{array}$ & $\mathrm{T}-\mathrm{S}$ & \\
\hline $\begin{array}{l}\text { Reading for specific } \\
\text { information }\end{array}$ & 10 minutes & $\begin{array}{l}\text { Now, ask SS to } \\
\text { unfold the handout } \\
\text { and answer the other } \\
\text { questions about Lucy } \\
\text { and her profession. } \\
\text { Monitor SS to assist } \\
\text { them when needed. } \\
\text { Ask them to check in } \\
\text { pairs. } \\
\text { Then, check with the } \\
\text { class. }\end{array}$ & $\begin{array}{l}\mathrm{S} \\
\mathrm{S}-\mathrm{S} \\
\mathrm{T}-\mathrm{SS}\end{array}$ & $\begin{array}{l}\text { Handout } \\
\text { Book page } 14\end{array}$ \\
\hline Genre analysis & 4 minutes & $\begin{array}{l}\text { Call SS' attention to } \\
\text { the type of genre } \\
\text { (poster) and ask them } \\
\text { where posters } \\
\text { circulate and the } \\
\text { reason. } \\
\text { (usually in a place } \\
\text { that there are people } \\
\text { interested in the info } \\
\text { provided. To inform } \\
\text { people about } \\
\text { something they might } \\
\text { be interested in) }\end{array}$ & $\mathrm{T}-\mathrm{SS}$ & \\
\hline Critical Thinking Time & 10 minutes & $\begin{array}{l}\text { Ask SS questions like } \\
\text { 'Would you like to be } \\
\text { a clown doctor?' 'Do } \\
\text { you think what they } \\
\text { do is important for } \\
\text { sick patients?' 'Do } \\
\text { they get paid or it is a } \\
\text { volunteer job?' 'Do } \\
\text { you or someone you } \\
\text { know do any other } \\
\text { kind of volunteer } \\
\text { jobs?' 'What do you } \\
\text { or the other people } \\
\text { do?' 'Is it important } \\
\text { to do volunteer } \\
\text { work?' 'Where can } \\
\text { we volunteer?' }\end{array}$ & $\mathrm{T}-\mathrm{SS}$ & \\
\hline
\end{tabular}


Volume 14 - Número 2 - ago/dez de 2019

\section{What does a clown doctor do?}

1) Let's check some vocabulary. Number the pictures according to the words below:

1. children

2. medicine

3. laughter

4. clown

5. smile

6. sick

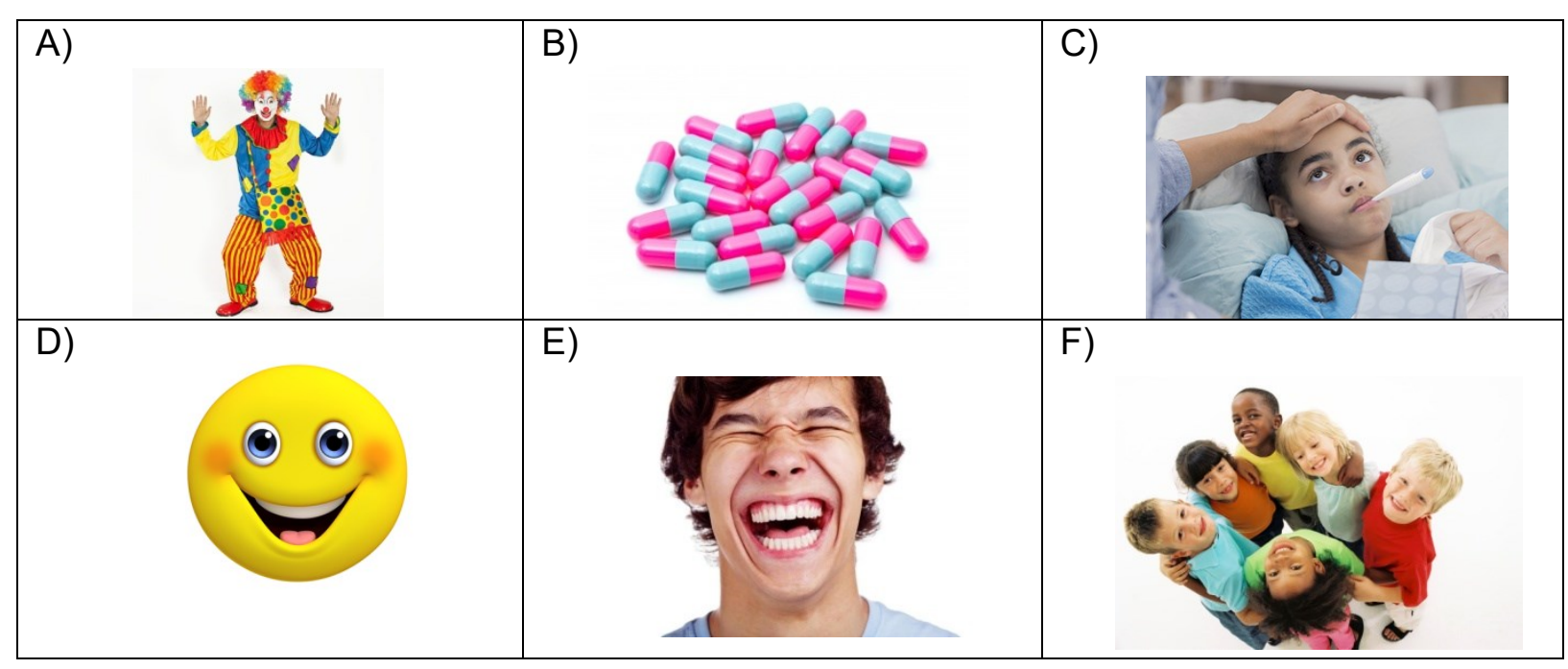

2) Read the poster one more time and answer the questions below:

1. How old is Lucy?

2. Where does she work?

3. Does she work with children or adults?

4. What type medicine does Lucy use to treat the patients?

5. Why does she use this medicine?

\section{GOING BEYOND...}

$\checkmark$ Pesquise informações sobre ONGs e outros lugares (escolas, hospitais, etc.) na sua região / bairro que precisam de pessoas para trabalhos voluntários. Reporte para a turma suas informações e escolha um lugar para um possível trabalho voluntário. 